\title{
Clustering Effects of Metabolic Factors and the Risk of Metabolic Syndrome
}

\author{
Yun-jin Kim, Hye-rim Hwang* \\ Department of Family Medicine, Pusan National University Hospital, Pusan National University School of Medicine, Busan, Korea
}

Background: Metabolic syndrome is a major risk factor for cardiovascular disease. Clustering of a combination of individual factors that increase the actual rather than the expected prevalence might be helpful in understanding the pathophysiology of metabolic syndrome. The aim of this study was to analyze the most influential factors for metabolic syndrome to assess clustering factors of metabolic syndrome.

Methods: Subjects from the Korea National Health and Nutrition Examination Survey (KNHANES) VI were included in the present study. The status of health behaviors was obtained using the questionnaires included in the KNHANES VI. A complex, stratified, and multistage sampling design was used to analyze the data according to statistics from the Korea Centers for Disease Control and Prevention.

Results: A total of 2,101 men and 2,831 women aged older than 20 years were included in this study. In men, drinking alcohol more than twice per week was related with the prevalence of metabolic syndrome; while, in women, exercise was related with the prevalence of metabolic syndrome. The clustering effect was observed for more than three metabolic factors. In men, the clustering effect was strongest for the combination of hypertension, hyperglycemia, and hypertriglyceridemia. In women, the strongest clustering effect was observed for the combination of abdominal obesity, hypertriglyceridemia, and low high-density lipoprotein cholesterol concentration.

Conclusion: The health behaviors affecting metabolic syndrome in men and women included drinking alcohol more than twice a week and exercising more than four times a week, respectively; in addition, hypertriglyceridemia most significantly influenced the clustering effect of metabolic syndrome.

Key words: Metabolic syndrome, Hypertriglyceridemia
Received June 22, 2018

Reviewed July 17, 2018

Accepted September 6, 2018

${ }^{*}$ Corresponding author Hye-rim Hwang

(iD) https://orcid.org/0000-0001-7658-3749

Department of Family Medicine, Pusan National University Hospital, Pusan National University School of Medicine, 179 Gudeok-ro, Seo-gu, Busan 49241. Korea

Tel: +82-51-240-7834

Fax: +82-51-240-7843

E-mail: hezera83@naver.com

\section{INTRODUCTION}

Metabolic syndrome is a major risk factor for type 2 diabetes mellitus and cardiovascular disease. Specifically, it increases the risk of incidence of type 2 diabetes mellitus by 3.53- to 5.17 -fold ${ }^{1,2}$ and that of the incidence of cardiovascular disease by 1.53 - to 2.18 fold. ${ }^{3}$ Furthermore, metabolic syndrome increases all-cause mortality by 1.27 - to 1.60 -fold. ${ }^{4}$ To promote public health and reduce mortality incidence, the establishment of management practices for metabolic syndrome is important. However, factors of metabolic syndrome vary according to definition, and whether metabolic syndrome is a disease sharing a pathogenesis remains unclear. ${ }^{5}$ As a result of these limitations, there is no consistent treatment recommendation. To elucidate the pathophysiology of metabolic syndrome, it could be helpful to understand the incidence differences of metabolic syndrome depending on the combination of individual factors of metabolic syndrome and to clarify if there is a discrepancy between the expected and actual prevalence of metabolic syndrome with a certain combination of individual factors. The combination of individual factors that increases the actual prevalence compared with the expected prevalence is defined as clustering. ${ }^{6}$ 
The aims of this study were to analyze the most influential factor related to the incidence of metabolic syndrome, to assess the clustering factors of metabolic syndrome, and to identify the pathogenesis of metabolic syndrome. The data were collected from responses to a health interview and nutrition surveys as well as the findings of health examinations. ${ }^{7}$

\section{METHODS}

\section{Study subjects}

Subjects from the Korea National Health and Nutrition Examination Survey (KNHANES) VI were used in the present study. The KNHANES VI was conducted by the Division of Chronic Disease Surveillance of the Korean Centers for Disease Control and Prevention in 2013 and includes nationally representative data. Subjects of the KNHANES VI who were aged older than 20 years numbered 2,592 men and 3,376 women. After excluding subjects without metabolic data (waist circumference, systolic and diastolic blood pressure, fasting plasma glucose concentration, triglyceride concentration, and high-density lipoprotein cholesterol [HDL-C] concentration) and health behavior data (smoking status, exercise, and alcohol drinking), the present study considered 2,101 men and 2,831 women. The Institutional Review Board of the Korea Centers for Disease Control and Prevention had previously reviewed and approved the KNHANES (IRB No. 2013-07CON-03-4C), and the need for informed consent for the current study was waived.

\section{Definition of metabolic syndrome}

Metabolic syndrome was defined according to the 2005 modified Adult Treatment Panel III by the American Heart Association and the National Heart, Lung, and Blood Institute. ${ }^{8}$ The criteria of abdominal obesity included a circumference $\geq 90 \mathrm{~cm}$ for men and $\geq 85 \mathrm{~cm}$ for women according to the Korean definition of abdominal obesity. ${ }^{9}$ Metabolic syndrome was diagnosed when three or more of the following were present: (1) waist circumference $\geq 90$ $\mathrm{cm}$ for men and $\geq 85 \mathrm{~cm}$ for women; (2) systolic blood pressure $\geq 130 \mathrm{mmHg}$, diastolic blood pressure $\geq 85 \mathrm{mmHg}$, or antihypertensive medication use; (3) fasting plasma glucose concentration $\geq 100 \mathrm{mg} / \mathrm{dL}$ or antidiabetic medication use; (4) triglyceride con- centration $\geq 150 \mathrm{mg} / \mathrm{dL}$ or anti-dyslipidemic medication use; (5) HDL-C concentration $<40 \mathrm{mg} / \mathrm{dL}$ for men and $<60 \mathrm{mg} / \mathrm{dL}$ for women or anti-dyslipidemic medication use.

\section{Definition of clustering}

The expected prevalence was calculated by multiplying the prevalence of each risk factor based on its incidence in the study subjects. A ratio of observed prevalence to expected prevalence $>1$ was defined as demonstrating clustering. ${ }^{6}$

\section{Health behaviors}

Information of health behaviors was obtained from responses to the questionnaires included in the KNHANES VI. Furthermore, the statuses of smoking, exercise, alcohol drinking, and perceived stress were analyzed. Smoking status was classified as either current smoker, ex-smoker, or nonsmoker. Exercise status was divided into three categories (none, three or fewer times a week, and more than four times a week). Alcohol drinking was classified according to the frequency of drinking per week, while perceived stress was classified according to degree.

\section{Statistical analysis}

A complex, stratified, multistage sampling design was used to analyze the data from the KNHANES VI according to the statistics from the Korea Centers for Disease Control and Prevention. Ordinary regression analysis was used to determine the relationships between health behaviors and metabolic factors and the number of metabolic factors. Logistic regression was used to identify the influence of health behaviors and metabolic factors on the occurrence of metabolic syndrome and clustering effects of metabolic factors in metabolic syndrome.

\section{RESULTS}

\section{Characteristics of the study subjects}

A total of 2,101 men and 2,831 women aged older than 20 years were included in this study. Most participants were between 40 and 59 years of age. The smoking status differed between the sexes; among men, the percentage of current smoker status was $40.1 \%$, which was the most common, while among women, nonsmokers 
made up $84.3 \%$ of the population. The proportion of respondents exercising over four days per week was $21.5 \%$ for men and $26.1 \%$ for women. Additionally, the rates of drinking alcohol more than

Table 1. Characteristics of the study population

\begin{tabular}{|c|c|c|c|c|}
\hline \multirow{2}{*}{ Variable } & \multicolumn{2}{|c|}{ Male $(n=2,101)$} & \multicolumn{2}{|c|}{ Female $(n=2,831)$} \\
\hline & No. ${ }^{*}(\%)$ & $95 \% \mathrm{Cl}$ & No. ${ }^{*}(\%)$ & $95 \% \mathrm{Cl}$ \\
\hline \multicolumn{5}{|l|}{ Age (yr) } \\
\hline $20-39$ & $588(28.0)$ & $35.9-42.2$ & $810(28.6)$ & $33.0-38.5$ \\
\hline $40-59$ & $792(37.7)$ & $39.9-45.4$ & $1,116(39.4)$ & $40.0-44.9$ \\
\hline$\geq 60$ & $721(34.3)$ & 16.5-20.4 & $905(32.0)$ & 19.6-24.3 \\
\hline \multicolumn{5}{|l|}{ Smoking } \\
\hline Current smoker & 794 (37.8) & $37.6-42.7$ & $127(4.5)$ & $3.9-6.3$ \\
\hline Ex-smoker & 741 (35.3) & $27.2-32.2$ & $140(4.9)$ & $4.6-6.6$ \\
\hline Nonsmoker & 416 (19.8) & $20.4-24.9$ & $2,419(85.4)$ & $82.1-86.2$ \\
\hline Other & $150(7.1)$ & $6.3-9.4$ & $145(5.1)$ & $4.2-6.6$ \\
\hline \multicolumn{5}{|l|}{ Exercise } \\
\hline Less than 3 days per week & $895(42.6)$ & $38.9-44.3$ & $1,201(42.4)$ & $39.1-43.9$ \\
\hline More than 4 days per week & $416(19.8)$ & 19.5-23.7 & $726(25.6)$ & 24.0-28.2 \\
\hline No & 574 (27.3) & $23.4-27.9$ & $674(23.8)$ & $21.8-25.8$ \\
\hline Other & $216(10.3)$ & $9.4-13.5$ & $230(8.1)$ & $7.2-10.4$ \\
\hline \multicolumn{5}{|l|}{ Alcohol drinking } \\
\hline No & $235(11.2)$ & 7.9-10.6 & $508(17.9)$ & $15.1-18.5$ \\
\hline Less than once per week & $897(42.7)$ & $42.8-49.0$ & $1,430(50.5)$ & $50.8-55.7$ \\
\hline More than twice per week & 709 (33.7) & $30.4-35.7$ & $303(10.7)$ & $10.2-13.0$ \\
\hline Other & 260 (12.4) & $10.4-13.7$ & $590(20.8)$ & 16.6-20.6 \\
\hline \multicolumn{5}{|l|}{ Perceived stress } \\
\hline Severe & $413(19.7)$ & $19.8-23.8$ & $706(24.9)$ & 24.1-28.1 \\
\hline Moderate & $1,157(55.1)$ & $53.4-58.4$ & $1,516(53.5)$ & $51.8-56.3$ \\
\hline Mild & 380 (18.1) & $12.9-16.5$ & $464(16.4)$ & 13.3-16.0 \\
\hline Other & $151(7.2)$ & $6.4-9.4$ & $145(5.1)$ & $4.2-6.6$ \\
\hline \multicolumn{5}{|l|}{$\begin{array}{l}\text { Frequency of abnormal } \\
\text { metabolic factor }\end{array}$} \\
\hline$W C \geq 90 \mathrm{~cm}(\mathrm{M})$ or $80 \mathrm{~cm}(\mathrm{~F})$ & $583(27.7)$ & $24.6-28.8$ & $1,150(40.6)$ & $34.0-39.7$ \\
\hline $\begin{aligned} \text { Sys } & \geq 130 \mathrm{mmHg} \text { or Dia } \\
& \geq 85 \mathrm{mmHg}\end{aligned}$ & $932(44.4)$ & $35.6-41.0$ & 922 (32.6) & $24.7-29.0$ \\
\hline$F B G \geq 100 \mathrm{mg} / \mathrm{dL}$ & $487(23.2)$ & $17.5-21.4$ & $415(14.7)$ & $11.3-13.9$ \\
\hline $\mathrm{TG} \geq 150 \mathrm{mg} / \mathrm{dL}$ & $947(45.1)$ & $42.0-47.0$ & $806(28.5)$ & $22.6-26.2$ \\
\hline $\begin{array}{l}\mathrm{HDL}-\mathrm{C}<40 \mathrm{mg} / \mathrm{dL}(\mathrm{M}) \text { or } \\
50 \mathrm{mg} / \mathrm{dL} \text { (F) }\end{array}$ & $447(21.3)$ & $18.0-21.8$ & $957(33.8)$ & $29.9-33.9$ \\
\hline \multicolumn{5}{|l|}{ No. of metabolic factors } \\
\hline 0 & $509(24.2)$ & $26.6-31.2$ & $927(32.7)$ & $34.9-39.9$ \\
\hline 1 & $555(26.4)$ & $23.5-28.1$ & $670(23.7)$ & $22.6-26.0$ \\
\hline 2 & $496(23.6)$ & $20.3-24.0$ & $520(18.4)$ & $16.2-19.8$ \\
\hline 3 & $357(17.0)$ & $14.1-17.5$ & $393(13.9)$ & $10.5-13.2$ \\
\hline 4 & $142(6.8)$ & $5.1-7.5$ & $244(8.6)$ & $5.6-7.5$ \\
\hline 5 & $42(2.0)$ & $0.9-1.8$ & $77(2.7)$ & $1.7-2.8$ \\
\hline $\begin{array}{l}\text { Presence of metabolic } \\
\text { syndrome }\end{array}$ & $541(25.7)$ & $21.4-25.3$ & 714 (25.2) & 18.8-22.2 \\
\hline
\end{tabular}

*Unweighted count.

$\mathrm{Cl}$, confidence interval; $\mathrm{WC}$, waist circumference; $\mathrm{M}$, male; F, female; Sys, systolic blood pressure; Dia, diastolic blood pressure; FBG, fasting blood glucose; TG, triglyceride; HDL-C, high-density lipoprotein cholesterol. twice a week were $33.0 \%$ for men and $11.5 \%$ for women, while the rate of perceived severe stress was $21.7 \%$ for men and $26.1 \%$ for women. In men, high serum triglyceride concentration was the most common metabolic risk factor versus abdominal obesity in women. The prevalence of metabolic syndrome was $23.3 \%$ and $20.5 \%$ in men and women, respectively (Table 1 ).

\section{Relationships among health behaviors, metabolic factors, and number of metabolic factors}

In women, health behaviors were not associated with increasing numbers of metabolic factors; however, in men, the number of metabolic factors was associated with current smoker status and alcohol consumption more than twice per week. The relationships between metabolic factors and number of metabolic factors were similar in the sexes. All metabolic factors were associated with an increasing number of metabolic factors and, among them, high triglyceride concentration was most related in both men and women (Table 2).

\section{The influence of health behaviors and metabolic factors on prevalence of metabolic syndrome}

The relationship of health behaviors and the prevalence of metabolic syndrome differed between men and women. In men, drinking alcohol more than twice per week was related with prevalence of metabolic syndrome compared to exercise in women. The relationship between metabolic factors and metabolic syndrome prevalence was comparable in both men and women; a high triglyceride concentration was most associated with prevalence of metabolic syndrome (Table 3).

\section{The clustering effects of metabolic factors in metabolic} syndrome

Table 4 shows the clustering effects of metabolic factors in metabolic syndrome. The clustering effect was observed with more than three metabolic factors. In men, the clustering effect of three metabolic factors appeared in three combinations. The first combination was abdominal obesity, hypertension, and hypertriglyceridemia; the second combination was abdominal obesity, hypertriglyceridemia, and low HDL-C concentration; and the third combination was hypertension, hyperglycemia, and hypertriglyceridemia. 
Table 2. The relations of health behaviors and metabolic factors with number of metabolic factors

\begin{tabular}{|c|c|c|c|c|}
\hline \multirow{2}{*}{ Health risk factor } & \multicolumn{2}{|r|}{ Male } & \multicolumn{2}{|c|}{ Female } \\
\hline & $\operatorname{Exp}(B)$ & $95 \% \mathrm{Cl}$ & $\operatorname{Exp}(B)$ & $95 \% \mathrm{Cl}$ \\
\hline \multicolumn{5}{|l|}{ Health behavior* } \\
\hline \multicolumn{5}{|l|}{ Smoking } \\
\hline Current smoker & 1.61 & $1.27-2.04$ & 1.52 & $0.94-2.45$ \\
\hline Ex-smoker & 1.24 & $0.94-1.62$ & 1.13 & $0.73-1.74$ \\
\hline Nonsmoker & 1.00 & & 1.00 & \\
\hline \multicolumn{5}{|l|}{ Exercise } \\
\hline Less than 3 days per week & 1.06 & $0.83-1.36$ & 0.88 & $0.71-1.08$ \\
\hline More than 4 days per week & 0.85 & $0.69-1.05$ & 0.81 & $0.66-0.99$ \\
\hline No & 1.00 & & 1.00 & \\
\hline \multicolumn{5}{|l|}{ Alcohol drinking } \\
\hline Less than once per week & 1.20 & $0.87-1.66$ & 0.96 & $0.74-1.25$ \\
\hline More than twice per week & 1.87 & $1.33-2.62$ & 1.03 & $0.75-1.40$ \\
\hline None & 1.00 & & 1.00 & \\
\hline \multicolumn{5}{|l|}{ Perceived stress } \\
\hline Severe & 1.12 & $0.80-1.55$ & 0.88 & $0.66-1.16$ \\
\hline Moderate & 1.05 & $0.81-1.36$ & 0.97 & $0.79-1.19$ \\
\hline Mild & 1.00 & & 1.00 & \\
\hline \multicolumn{5}{|l|}{ Metabolic factor ${ }^{\dagger}$} \\
\hline \multicolumn{5}{|l|}{ WC } \\
\hline$\geq 90 \mathrm{~cm}(\mathrm{M})$ or $80 \mathrm{~cm}(\mathrm{~F})$ & 16.19 & 12.89-20.32 & 21.14 & $17.15-26.06$ \\
\hline Normal & 1.00 & & 1.00 & \\
\hline \multicolumn{5}{|l|}{ Hypertension } \\
\hline $\begin{array}{c}\text { Sys } \geq 130 \mathrm{mmHg} \text { or } \\
\text { Dia } \geq 85 \mathrm{mmHg}\end{array}$ & 10.93 & $9.20-12.99$ & 9.71 & 7.83-12.03 \\
\hline Normal & 1.00 & & 1.00 & \\
\hline \multicolumn{5}{|l|}{ Hyperglycemia } \\
\hline $\mathrm{FBG} \geq 100 \mathrm{mg} / \mathrm{dL}$ & 12.02 & $9.56-15.12$ & 18.46 & $14.18-24.04$ \\
\hline Normal & 1.00 & & 1.00 & \\
\hline \multicolumn{5}{|l|}{ High TG } \\
\hline $\mathrm{TG} \geq 150 \mathrm{mg} / \mathrm{dL}$ & 28.39 & 22.15-36.39 & 27.41 & 21.97-34.19 \\
\hline Normal & 1.00 & & 1.00 & \\
\hline \multicolumn{5}{|l|}{ Low HDL-C } \\
\hline $\begin{array}{l}\mathrm{HDL}-\mathrm{C}<40 \mathrm{mg} / \mathrm{dL} \text { (M) or } \\
50 \mathrm{mg} / \mathrm{dL} \text { (F) }\end{array}$ & 10.33 & 8.34-12.79 & 16.05 & $13.21-19.49$ \\
\hline Normal & 1.00 & & 1.00 & \\
\hline
\end{tabular}

*Ordinary regression; subpopulation: sex=male/female, dependent variable: number of metabolic factors (ascending), model: smoking, exercise, alcohol drinking, and perceived stress, with covariance of age. Link function: logit; 'Ordinary regression; subpopulation: sex=male/female, dependent variable: number of metabolic factors (ascending), model: one metabolic factor among WC, hypertension, hyperglycemia, high triglycerides, and low HDL-C, with covariance of age. Link function: logit.

$\mathrm{Cl}$, confidence interval; WC, waist circumference; $\mathrm{M}$, male; F, female; Sys, systolic blood pressure; Dia, diastolic blood pressure; FBG, fasting blood glucose; TG, triglyceride; HDL-C, high-density lipoprotein cholesterol.

The clustering effect in men was strongest for the third combination. In women, the clustering effect of three metabolic factors was observed for two combinations. The first combination was abdominal obesity, hypertension, and hypertriglyceridemia, while the
Table 3. The influence of health behaviors and metabolic factors on prevalence of metabolic syndrome

\begin{tabular}{|c|c|c|c|c|}
\hline \multirow{2}{*}{ Variable } & \multicolumn{2}{|r|}{ Male } & \multicolumn{2}{|c|}{ Female } \\
\hline & OR & $95 \% \mathrm{Cl}$ & $\mathrm{OR}$ & $95 \% \mathrm{Cl}$ \\
\hline \multicolumn{5}{|l|}{ Health behavior* } \\
\hline \multicolumn{5}{|l|}{ Smoking } \\
\hline Current smoker & 1.25 & $0.89-1.75$ & 1.37 & $0.80-2.35$ \\
\hline Ex-smoker & 1.12 & $0.75-1.67$ & 1.31 & $0.68-2.50$ \\
\hline Nonsmoker & 1.00 & & 1.00 & \\
\hline \multicolumn{5}{|l|}{ Exercise } \\
\hline Less than 3 days per week & 1.16 & $0.84-1.58$ & 1.07 & $0.80-1.43$ \\
\hline More than 4 days per week & 1.03 & $0.68-1.57$ & 0.77 & $0.60-0.98$ \\
\hline No & 1.00 & & 1.00 & \\
\hline \multicolumn{5}{|l|}{ Alcohol drinking } \\
\hline Less than once per week & 0.99 & $0.66-1.46$ & 0.93 & $0.67-1.28$ \\
\hline More than twice per week & 1.66 & $1.12-2.46$ & 0.84 & $0.54-1.31$ \\
\hline None & 1.00 & & 1.00 & \\
\hline \multicolumn{5}{|l|}{ Perceived stress } \\
\hline Severe & 1.07 & $0.71-1.61$ & 0.98 & $0.70-1.38$ \\
\hline Moderate & 0.97 & $0.70-1.34$ & 0.93 & $0.73-1.71$ \\
\hline Mild & 1.00 & & 1.00 & \\
\hline \multicolumn{5}{|l|}{ Metabolic factor ${ }^{\dagger}$} \\
\hline \multicolumn{5}{|l|}{ WC } \\
\hline$\geq 90 \mathrm{~cm}(\mathrm{M})$ or $80 \mathrm{~cm}(\mathrm{~F})$ & 13.54 & $10.21-17.94$ & 14.29 & 11.02-18.53 \\
\hline Normal & 1.00 & & 1.00 & \\
\hline \multicolumn{5}{|l|}{ Hypertension } \\
\hline $\begin{array}{c}\text { Sys } \geq 130 \mathrm{mmHg} \text { or } \\
\text { Dia } \geq 85 \mathrm{mmHg}\end{array}$ & 9.69 & $7.58-12.38$ & 7.10 & $5.37-9.40$ \\
\hline Normal & 1.00 & & 1.00 & \\
\hline \multicolumn{5}{|l|}{ Hyperglycemia } \\
\hline$F B G \geq 100 \mathrm{mg} / \mathrm{dL}$ & 11.11 & 8.39-14.71 & 14.97 & 10.67-21.01 \\
\hline Normal & 1.00 & & 1.00 & \\
\hline \multicolumn{5}{|l|}{ High TG } \\
\hline $\mathrm{TG} \geq 150 \mathrm{mg} / \mathrm{dL}$ & 17.01 & $12.20-23.73$ & 22.97 & $17.25-30.59$ \\
\hline Normal & 1.00 & & 1.00 & \\
\hline \multicolumn{5}{|l|}{ Low HDL-C } \\
\hline $\begin{array}{l}\mathrm{HDL}-\mathrm{C}<40 \mathrm{mg} / \mathrm{dL} \text { (M) or } \\
50 \mathrm{mg} / \mathrm{dL} \text { (F) }\end{array}$ & 7.39 & 5.63-9.71 & 9.88 & $7.62-12.83$ \\
\hline Normal & 1.00 & & 1.00 & \\
\hline
\end{tabular}

*Logistic regression; subpopulation: sex=male/female, dependent variable: presence of metabolic syndrome (reference category=normal), model: one factor among smoking, exercise, alcohol drinking, perceived stress, and age; 'Logistic regression; subpopulation: sex=male/female, dependent variable: presence of metabolic syndrome (reference category=normal), model: one factor among WC, hypertension, hyperglycemia, high triglyceride, low HDL-C with covariance of age.

$\mathrm{OR}$, odds ratio; $\mathrm{Cl}$, confidence interval; $\mathrm{WC}$, waist circumference; $\mathrm{M}$, male; $\mathrm{F}$, female; Sys, systolic blood pressure; Dia, diastolic blood pressure; FBG, fasting blood glucose; TG, triglyceride; HDL-C, high-density lipoprotein cholesterol.

second combination was abdominal obesity, hypertriglyceridemia, and low HDL-C concentration. The clustering effect in women was stronger for the second combination. The clustering effect of four metabolic factors was observed in all combinations in women 
Table 4. The clustering effects of metabolic factors in metabolic syndrome

\begin{tabular}{|c|c|c|c|c|c|c|c|c|c|c|c|}
\hline \multirow{2}{*}{$\begin{array}{l}\text { No. of } \\
\text { metabolic } \\
\text { factors }\end{array}$} & \multicolumn{5}{|c|}{ Abnormal metabolic factor } & \multicolumn{3}{|c|}{ Male } & \multicolumn{3}{|c|}{ Female } \\
\hline & WC & $\mathrm{HP}$ & Glu & TG & HDL-C & $\begin{array}{c}\text { Frequency } \\
\text { (observed/expected) }\end{array}$ & O/E & $95 \% \mathrm{Cl}$ & $\begin{array}{c}\text { Frequency } \\
\text { (observed/expected) }\end{array}$ & O/E & $95 \% \mathrm{Cl}$ \\
\hline \multirow[t]{5}{*}{1} & + & - & - & - & - & $3.8 / 5.9$ & 0.65 & $0.51-0.82$ & $8.4 / 12.2$ & 0.69 & $0.58-0.82$ \\
\hline & - & + & - & - & - & $9.0 / 10.1$ & 0.89 & $0.77-1.03$ & $4.9 / 7.6$ & 0.65 & $0.53-0.79$ \\
\hline & - & - & + & - & - & 2.0/3.9 & 0.50 & $0.36-0.70$ & $0.8 / 3.0$ & 0.28 & $0.18-0.42$ \\
\hline & - & - & - & + & - & $8.2 / 13.0$ & 0.63 & $0.52-0.77$ & $2.1 / 6.7$ & 0.31 & $0.24-0.40$ \\
\hline & - & - & - & - & + & $2.7 / 4.0$ & 0.68 & $0.48-0.95$ & $8.0 / 9.7$ & 0.82 & $0.71-0.94$ \\
\hline \multirow[t]{10}{*}{2} & + & + & - & - & - & $2.3 / 3.7$ & 0.64 & $0.47-0.87$ & $3.6 / 4.4$ & 0.81 & $0.64-1.01$ \\
\hline & + & - & + & - & - & $0.6 / 1.4$ & 0.40 & $0.21-0.75$ & $0.9 / 1.7$ & 0.50 & $0.33-0.78$ \\
\hline & + & - & - & + & - & $3.6 / 4.7$ & 0.76 & $0.56-1.01$ & $1.9 / 3.9$ & 0.50 & $0.35-0.69$ \\
\hline & + & - & - & - & + & $0.6 / 1.5$ & 0.41 & $0.23-0.75$ & $4.6 / 5.7$ & 0.81 & $0.66-1.00$ \\
\hline & - & + & + & - & - & $1.7 / 2.4$ & 0.69 & $0.51-0.94$ & $0.7 / 1.1$ & 0.64 & $0.40-1.04$ \\
\hline & - & + & - & + & - & $6.0 / 8.1$ & 0.74 & $0.62-0.89$ & $1.6 / 2.5$ & 0.66 & $0.47-0.93$ \\
\hline & - & + & - & - & + & $0.9 / 2.5$ & 0.35 & $0.20-0.61$ & $1.4 / 3.6$ & 0.38 & $0.26-0.56$ \\
\hline & - & - & + & + & - & $2.1 / 3.1$ & 0.68 & $0.49-0.94$ & $0.2 / 1.0$ & 0.17 & $0.05-0.59$ \\
\hline & - & - & + & - & + & $0.4 / 1.0$ & 0.37 & $0.18-0.79$ & $0.4 / 1.4$ & 0.31 & $0.17-0.56$ \\
\hline & - & - & - & + & + & $4.0 / 3.2$ & 1.24 & $0.97-1.60$ & 2.6/3.1 & 0.83 & $0.63-1.10$ \\
\hline \multirow[t]{10}{*}{3} & + & + & + & - & - & $1.2 / 0.9$ & 1.34 & $0.84-2.15$ & $0.9 / 0.6$ & 1.40 & $0.90-2.17$ \\
\hline & + & + & - & + & - & $4.4 / 2.9$ & 1.49 & 1.17-1.88 & $2.4 / 1.4$ & 1.66 & $1.29-2.14$ \\
\hline & + & + & - & - & + & $0.5 / 0.9$ & 0.57 & $0.30-1.09$ & $1.7 / 2.1$ & 0.81 & $0.62-1.06$ \\
\hline & + & - & + & + & - & $1.2 / 1.1$ & 1.04 & $0.69-1.56$ & $0.6 / 0.6$ & 1.01 & $0.58-1.78$ \\
\hline & + & - & + & - & + & $0.4 / 0.3$ & 1.10 & $0.46-2.62$ & $0.7 / 0.8$ & 0.85 & $0.49-1.49$ \\
\hline & + & - & - & + & + & $1.6 / 1.2$ & 1.40 & $1.00-1.94$ & $3.2 / 1.8$ & 1.73 & $1.37-2.19$ \\
\hline & - & + & + & + & - & $3.2 / 1.9$ & 1.62 & $1.22-2.16$ & $0.5 / 0.4$ & 1.33 & $0.79-2.23$ \\
\hline & - & + & + & - & + & $0.3 / 0.6$ & 0.42 & $0.21-0.83$ & $0.5 / 0.5$ & 0.93 & $0.47-1.84$ \\
\hline & - & + & - & + & + & $2.0 / 2.0$ & 1.01 & $0.71-1.43$ & $1.1 / 1.1$ & 0.99 & $0.71-1.37$ \\
\hline & - & - & + & + & + & $1.1 / 0.8$ & 1.41 & $0.90-2.21$ & $0.3 / 0.4$ & 0.72 & $0.37-1.39$ \\
\hline \multirow[t]{5}{*}{4} & + & + & + & + & - & $2.1 / 0.7$ & 3.01 & $2.21-4.09$ & $1.3 / 0.2$ & 6.28 & $4.76-8.27$ \\
\hline & + & + & + & - & + & $0.4 / 0.2$ & 1.86 & $0.88-3.91$ & $0.8 / 0.3$ & 2.68 & $1.88-3.82$ \\
\hline & + & + & - & + & + & $2.1 / 0.7$ & 2.86 & 2.04-3.99 & $2.6 / 0.7$ & 3.85 & $3.03-4.90$ \\
\hline & + & - & + & + & + & $0.6 / 0.3$ & 2.12 & $1.22-3.67$ & $1.1 / 0.3$ & 4.37 & $3.04-6.27$ \\
\hline & - & + & + & + & + & $1.0 / 0.5$ & 2.11 & $1.35-3.30$ & $0.7 / 0.2$ & 4.19 & $2.49-7.06$ \\
\hline 5 & + & + & + & + & + & $1.3 / 0.2$ & 7.36 & 5.27-10.25 & $2.2 / 0.1$ & 22.83 & $17.69-29.42$ \\
\hline
\end{tabular}

WC, waist circumference; HP, hypertension; Glu, hyperglycemia; TG, triglyceride; HDL-C, high-density lipoprotein cholesterol; 0/E, ratio of observed prevalence to expected prevalence; $\mathrm{Cl}$, confidence interval.

but was not observed in combinations not including hypertriglyceridemia in men.

\section{DISCUSSION}

Clustering is defined as a situation in which the actual prevalence of disease according to individual risk factors is higher than the expected prevalence according to the same individual risk factors. ${ }^{5}$ Metabolic syndrome, which is presented as a co-occurrence of metabolic risk factors for both type 2 diabetes mellitus and cardio- vascular disease, is a representative clustering disease, with its pathogenesis based on insulin resistance. ${ }^{10}$ Hyperinsulinemia appearing in response to insulin resistance may play a key role in the occurrence of hypertension, high low-density lipoprotein cholesterol concentration, low HDL-C concentration, and type 2 diabetes mellitus. Insulin resistance is associated with lower adiponectin, which reduces serum free fatty acid concentration and inflammation. ${ }^{11}$ The aim of this study was to investigate the role of health behaviors and metabolic factors in the development of metabolic syndrome and to evaluate the clustering effect of metabolic risk 
factors.

In the present study, among several health behaviors, drinking alcohol was significantly associated with an increase in metabolic risk factors in men. Notably, the metabolic risk factors increased in men who drank more than twice a week. In a previous study ${ }^{12}$, the rates of abdominal obesity and serum concentration of HDL-C were higher in participants with an alcohol consumption $>200 \mathrm{~g}$ per week versus in those with a lower level of alcohol consumption. In other words, alcohol consumption was a risk factor for abdominal obesity but not for cholesterol metabolism. Separately, a meta-anal$\mathrm{ysis}^{13}$ reported that the risk of metabolic syndrome was lower in very light drinkers $(0.1-5 \mathrm{~g} /$ day $)$ versus in nondrinkers; however, the risk of metabolic syndrome was higher in heavy drinkers than in nondrinkers. In subgroup analysis, this J-shaped trend was remarkable in men but not in women. Unlike in previous studies, the J-shaped relationship between amount of alcohol consumption and number of metabolic risk factors was not observed in this study, which is probably due to our method of categorization of alcohol consumption. By increasing the risk of metabolic factors, including blood pressure, glucose metabolism, hypertriglyceridemia, and abdominal obesity, alcohol drinking increased the risk of metabolic syndrome. ${ }^{14,15}$ In this study, the relationship was observed only in men and was not concordant with the findings of previous studies because of the low prevalence of alcohol consumption in women.

On the other hand, exercising more than four times a week decreased the number of metabolic risk factors and the prevalence of metabolic syndrome in women but not in men. A disparity of sex in the relationship between physical activity and metabolic syndrome has been reported previously. ${ }^{16}$ Another study ${ }^{17}$ reported that rigorous physical activity decreased the risk of metabolic syndrome in both sexes, but that moderate physical activity decreased the risk of metabolic syndrome only in women. The mechanism of this disparity was explained by the existing biological differences in men and women. ${ }^{18-20}$ Specifically, the amounts of fat, free fatty acids, and intramuscular fat are higher in women than in men; however, the amount of skeletal muscle mass is two-thirds lower in women than in men. ${ }^{21}$ Furthermore, the total physical activity of women was less than that of men. Thus, it is anticipated that insulin resistance is stronger in women than in men. ${ }^{22}$ However, the insulin sensitivity values of men and women were similar in a previous study. ${ }^{23}$ Despite the sex variations in total physical activity and body composition, glucose disposal was similar between men and women. This result might be the result of enhanced glucose effectiveness in women. In women, glucose homeostasis is somewhat influenced by maintenance of serum estrogen within a narrow range. Therefore, in postmenopausal women, this effect disappears. ${ }^{21,22}$

In this study, hypertriglyceridemia was the metabolic factor most associated with prevalence of metabolic syndrome in both sexes. In a previous study ${ }^{23}$, hypertriglyceridemia $(\geq 150 \mathrm{mg} / \mathrm{dL}$ ) was suggested as a criterion for distinguishing prediabetes subjects according to risk of metabolic and cardiovascular diseases. The prediabetic subjects were insulin-resistant, and their risk of metabolic and cardiovascular diseases ranged broadly; therefore, criteria to assess the risk of metabolic and cardiovascular diseases are needed. Similar to our study, hypertriglyceridemia was proposed as a criterion based on its relationship with metabolic risk. In the current study, we analyzed the prevalence of metabolic syndrome for each metabolic risk factor and observed that the prevalence of metabolic syndrome was much higher in subjects with hypertriglyceridemia than in subjects with other risk factors for both sexes. As a result, we suggested that hypertriglyceridemia was the most useful indicator of insulin resistance due to its role in the pathogenesis of metabolic syndrome versus the other metabolic risk factors. In other words, reducing serum triglyceride concentration may reduce metabolic risk.

The influence of hypertriglyceridemia was also apparent in the clustering effect of metabolic risk factors for metabolic syndrome. A clustering effect was not observed in cases of one or two risk factors because the expected prevalence of metabolic syndrome was not higher than the actual prevalence. This was a predictable result because the diagnostic criteria for metabolic syndrome require three or more risk factors. Therefore, the clustering effect, where the actual prevalence was higher than the expected prevalence, was observed in groups with more than four risk factors except in the case of one combination of risk factors. The clustering effect was observed only with the combination of four risk factors including hypertriglyceridemia in men; thus, hypertriglyceridemia influenced the prevalence of metabolic syndrome more in men than in women. Meanwhile, among the combinations of three risk factors, a 
clustering effect was observed in the case of the triad of abdominal obesity, high blood pressure, and hypertriglyceridemia in both sexes. A clustering effect was also observed in the combination of hypertriglyceridemia, high blood pressure, and high fasting glucose in men and in the combination of hypertriglyceridemia, abdominal obesity, and low HDL-C in women. The combination of abdominal obesity, high blood pressure, and hypertriglyceridemia, which was common in both sexes in the present study, was also a prevalent clustering example in England, part of Italy, and Germany, with high reported prevalence. ${ }^{24}$ In the current study, the combinations with clustering effects were diverse; however, all included hypertriglyceridemia. Previous studies ${ }^{25,26}$ have reported that the combination of abdominal obesity and hypertriglyceridemia is most applicable for predicting the risk of type 2 diabetes mellitus and cardiovascular risk. Similar to these past studies, the importance of these two risk factors, especially hypertriglyceridemia, was identified. Notably, the mechanism for their importance was unclear but appeared to be the result of free fatty acid metabolism in the liver. We assumed that increased visceral fat in abdominal obesity promotes the secretion of triglycerides in the liver, resulting in insulin resistance. ${ }^{27}$ In other words, insulin resistance was initially induced by abdominal obesity, but there is an intermediate step of hypertriglyceridemia. Consequently, combinations including hypertriglyceridemia were more often observed in clustering, and the prevalence of metabolic syndrome was higher in those combinations. Thus, subjects with hypertriglyceridemia, regardless of sex, should be managed appropriately to reduce their risk of metabolic syndrome.

While hypertriglyceridemia was the most influential factor in both sexes, the second most influential factor was different between men and women, as follows: high blood pressure in men and abdominal obesity in women. A previous meta-anlysis ${ }^{28}$ reported similar results in that hypertension was the most prevalent factor of metabolic syndrome in men, while the most prevalent factor of metabolic syndrome for women was central obesity. One animal study ${ }^{29}$ reported that females were protected from the renin-angiotensin system by central estrogen and its regulation. In addition, a protective effect of female sex hormones was explained by chronic inflammation. ${ }^{30}$ Estrogen receptors are located on the surface of immune cells and could regulate the immune response; thus, estro- gen might play an important role in inducing an anti-inflammatory reaction to protect against hypertension and, through this, could lead to a sex difference regarding metabolic clustering.

The strength of this study was its use of representative data from Korea. However, there are several limitations. First, this study was cross-sectional in nature and thus cannot reveal causality. Second, because health behaviors were investigated using questionnaires, there was a risk of subjective answer. Third, the quality of the health behaviors could not be measured.

In conclusion, the health behaviors that affected metabolic syndrome in men and women were drinking alcohol more than twice a week and exercising more than four times a week, respectively; in addition, hypertriglyceridemia most significantly influenced the clustering effect of metabolic syndrome.

\section{CONFLICTS OF INTEREST}

The authors declare no conflict of interest.

\section{ACKNOWLEDGMENTS}

This work was supported by a 2-year research grant from Pusan National University.

\section{REFERENCES}

1. Ford ES, Li C, Sattar N. Metabolic syndrome and incident diabetes: current state of the evidence. Diabetes Care 2008;31: 1898-904.

2. Lee ES, Oh SW, Yoon YS. Metabolic syndrome defined by International Diabetes Federation (IDF) or National Cholesterol Education Program (NCEP) and insulin resistance. Korean J Obes 2006;15:91-7.

3. Galassi A, Reynolds K, He J. Metabolic syndrome and risk of cardiovascular disease: a meta-analysis. Am J Med 2006;119: 812-9.

4. Ford ES. Risks for all-cause mortality, cardiovascular disease, and diabetes associated with the metabolic syndrome: a summary of the evidence. Diabetes Care 2005;28:1769-78.

5. Kahn R, Buse J, Ferrannini E, Stern M; American Diabetes 
Association; European Association for the Study of Diabetes. The metabolic syndrome: time for a critical appraisal: joint statement from the American Diabetes Association and the European Association for the Study of Diabetes. Diabetes Care 2005;28:2289-304.

6. Schuit AJ, van Loon AJ, Tijhuis M, Ocké M. Clustering of lifestyle risk factors in a general adult population. Prev Med 2002; $35: 219-24$.

7. Korea Centers for Disease Control and Prevention. Korea National Health and Nutrition Examination Survey (KNHANES IV, V-1,2). Cheongju: Korea Centers for Disease Control and Prevention; 2012.

8. Grundy SM, Cleeman JI, Daniels SR, Donato KA, Eckel RH, Franklin BA, et al. Diagnosis and management of the metabolic syndrome: an American Heart Association/National Heart, Lung, and Blood Institute Scientific Statement. Circulation 2005;112:2735-52.

9. Lee SY, Park HS, Kim DJ, Han JH, Kim SM, Cho GJ, et al. Appropriate waist circumference cutoff points for central obesity in Korean adults. Diabetes Res Clin Pract 2007;75:72-80.

10. Eckel RH, Grundy SM, Zimmet PZ. The metabolic syndrome. Lancet 2005;365:1415-28.

11. Mantzoros CS, Li T, Manson JE, Meigs JB, Hu FB. Circulating adiponectin levels are associated with better glycemic control, more favorable lipid profile, and reduced inflammation in women with type 2 diabetes. J Clin Endocrinol Metab 2005; 90:4542-8.

12. Lee WY, Jung CH, Park JS, Rhee EJ, Kim SW. Effects of smoking, alcohol, exercise, education, and family history on the metabolic syndrome as defined by the ATP III. Diabetes Res Clin Pract 2005;67:70-7.

13. Sun K, Ren M, Liu D, Wang C, Yang C, Yan L. Alcohol consumption and risk of metabolic syndrome: a meta-analysis of prospective studies. Clin Nutr 2014;33:596-602.

14. Corrao G, Bagnardi V, Zambon A, La Vecchia C. A meta-analysis of alcohol consumption and the risk of 15 diseases. Prev Med 2004;38:613-9.

15. Tolstrup JS, Heitmann BL, Tjønneland AM, Overvad OK, Sørensen TI, Grønbaek MN. The relation between drinking pattern and body mass index and waist and hip circumference.
Int J Obes (Lond) 2005;29:490-7.

16. Després JP, Pouliot MC, Moorjani S, Nadeau A, Tremblay A, Lupien PJ, et al. Loss of abdominal fat and metabolic response to exercise training in obese women. Am J Physiol 1991;261(2 Pt 1):E159-67.

17. Xiao J, Shen C, Chu MJ, Gao YX, Xu GF, Huang JP, et al. Physical activity and sedentary behavior associated with components of metabolic syndrome among people in rural China. PLoS One 2016;11:e0147062.

18. Sattelmair J, Pertman J, Ding EL, Kohl HW 3rd, Haskell W, Lee IM. Dose response between physical activity and risk of coronary heart disease: a meta-analysis. Circulation 2011;124: 789-95.

19. Bassuk SS, Manson JE. Physical activity and cardiovascular disease prevention in women: a review of the epidemiologic evidence. Nutr Metab Cardiovasc Dis 2010;20:467-73.

20. Lee IM, Rexrode KM, Cook NR, Manson JE, Buring JE. Physical activity and coronary heart disease in women: is "no pain, no gain” passé? JAMA 2001;285:1447-54.

21. Mauvais-Jarvis F. Sex differences in metabolic homeostasis, diabetes, and obesity. Biol Sex Differ 2015;6:14.

22. Basu R, Dalla Man C, Campioni M, Basu A, Klee G, Toffolo G, et al. Effects of age and sex on postprandial glucose metabolism: differences in glucose turnover, insulin secretion, insulin action, and hepatic insulin extraction. Diabetes 2006;55:200114.

23. Abbasi F, Kohli P, Reaven GM, Knowles JW. Hypertriglyceridemia: a simple approach to identify insulin resistance and enhanced cardio-metabolic risk in patients with prediabetes. Diabetes Res Clin Pract 2016;120:156-61.

24. Scuteri A, Laurent S, Cucca F, Cockcroft J, Cunha PG, Mañas LR, et al. Metabolic syndrome across Europe: different clusters of risk factors. Eur J Prev Cardiol 2015;22:486-91.

25. Lee BJ, Kim JY. Identification of type 2 diabetes risk factors using phenotypes consisting of anthropometry and triglycerides based on machine learning. IEEE J Biomed Health Inform 2016;20:39-46.

26. Poirier J, Kubow S, Noël M, Dupont C, Egeland GM. The hypertriglyceridemic-waist phenotype is associated with the Framingham risk score and subclinical atherosclerosis in $\mathrm{Ca}-$ 
nadian Cree. Nutr Metab Cardiovasc Dis 2015;25:1050-5.

27. Sam S, Haffner S, Davidson MH, D’Agostino RB Sr, Feinstein S, Kondos G, et al. Hypertriglyceridemic waist phenotype predicts increased visceral fat in subjects with type 2 diabetes. Diabetes Care 2009;32:1916-20.

28. Li R, Li W, Lun Z, Zhang H, Sun Z, Kanu JS, et al. Prevalence of metabolic syndrome in mellitus mainland China: a metaanalysis of published studies. BMC Public Health 2016;16:296.
29.Xue B, Zhang Z, Beltz TG, Guo F, Hay M, Johnson AK. Estrogen regulation of the brain renin-angiotensin system in protection against angiotensin II-induced sensitization of hypertension. Am J Physiol Heart Circ Physiol 2014;307:H191-8.

30. Taylor LE, Sullivan JC. Sex differences in obesity-induced hypertension and vascular dysfunction: a protective role for estrogen in adipose tissue inflammation? Am J Physiol Regul Integr Comp Physiol 2016;311:R714-20. 